\title{
Comparison of two intelligent models to estimate the instantaneous global solar radiation in semi-arid climate conditions: Application in Iran
}

\author{
Mostafa Zamani Mohiabadi ${ }^{1,{ }^{*}}$ and Mohsen Mirzaei ${ }^{2}$ \\ ${ }^{1}$ Research Department of High Temperature Fuel Cell, Vali-e-Asr University of Rafsanjan, Rafsanjan, Iran. \\ ${ }^{2}$ Department of Engineering, Vali-e-Asr University of Rafsanjan, Rafsanjan, Iran. \\ *Corresponding author. e-mail: m.zamani@vru.ac.ir
}

MS received 31 May 2016; revised 24 February 2017; accepted 28 February 2017; published online 25 July 2017

Solar radiation incident on the earth's surface is a fundamental input for many aspects of climatology, hydrology, biology, and architecture. In addition, it is an important parameter in solar energy applications. Due to the high cost of the measuring instruments of solar radiation, many researchers have suggested different empirical methods to estimate this essential parameter. In this study, with the help of fuzzy systems and neural networks, two models have been designed to estimate the instantaneous global solar radiation in Rafsanjan city which has a typical climatic conditions of semi-arid region of middle eastern countries. In fuzzy and neural network model, the inputs are the number of the given day in the year, time, ambient temperature and cloudiness, The comparison between the results of the models and the measurements, shows that the estimated global radiation is similar to the measurement; for fuzzy model, statistical indicators RMSE, MBE and t-test are $103.4367\left(\mathrm{w} / \mathrm{m}^{2}\right), 4.1169\left(\mathrm{w} / \mathrm{m}^{2}\right)$ and 9.1318 , respectively and for ANN, they are $85.46\left(\mathrm{w} / \mathrm{m}^{2}\right), 3.08\left(\mathrm{w} / \mathrm{m}^{2}\right)$ and 5.41 , respectively. As the results indicate, both models are able to estimate the amount of radiation well, while the neural network has a higher accuracy. The output of the modes for six other cities of Iran, with similar climate conditions, also proves the ability of the proposed models.

Keywords. Global solar radiation; fuzzy; neural network.

\section{Introduction}

Solar radiation data are important tools for many areas of research and applications in various engineering fields, and is dependent on different causes, including astronomical and meteorological factors (Sabziparvar 2008). The most reliable way to measure the solar radiation is by installing Pyranometers in stations to record global solar irradiation data and the amount of solar radiation that reaches the earth's surface (El Mghouchi et al. 2014). In the absence of a measuring instrument, particularly, in arid and semi-arid regions where the number of solar observation sites is poor, accurate and reliable solar radiation data is not available.

Using estimating tools such as solar models is one of the best methods to have a good solar potential investigation (Azadeh et al. 2009). Because of the stochastic behaviour of wind and solar data, accurate data modelling and successful sizing of the system are difficult (Behrang et al. 2010).

So far, different models, including empirical (Filho et al. 2016), Fuzzy logic (Bhardwaj et al. 2013), and intelligent methods (Mallet et al. 2011) have been developed to estimate instantaneously, daily or monthly global solar radiation, using 
different meteorological variables, at different regions in the world. The availability of meteorological parameters, which are used as the input of radiation models, is the important key to choose the proper radiation models at any location (Sabziparvar 2008). One of the earliest empirical models for global solar radiation have been done by Victor H Quej (Quej et al. 2016) who evaluated the accuracy and applicability of 13 different empirical global solar radiation models for warm subhumid regions, according to the daily meteorological data in Mexico. They have proposed a newly developed model, based on temperature, rainfall and air humidity, which performs better than models that used temperature data only. Another research (Yacef et al. 2014) has combined empirical models and a Bayesian neural network (BNN) model to estimate daily global solar radiation on a horizontal surface in Ghardaïa, Algeria. In their model, the maximum and minimum air temperatures of the year 2006 have been used to estimate the coefficients of the empirical models, as well as to train the BNN model. Their model has a good accuracy for that particular location. An artificial neural network (ANN) provides a computationally efficient way to determine an empirical, possibly nonlinear relationship between a number of inputs and one or more outputs. There are different applications of ANN, which are generally used for modelling, identification, optimization, prediction, forecasting and control of complex systems. In solar radiation modelling and prediction, many studies have been performed using an ANN (Benghanem et al. 2009). Alvaro LinaresRodríguez (Linares-Rodríguez et al. 2011) used ANN techniques to predict the daily global solar radiation by using the input as geographical location (latitude, longitude), the day of the year, the daily clear sky global radiation, and the four meteorological variables of Andalusia (Spain), while the daily global solar radiation was the only output of the ANN. The optimum network architecture yielded a root mean square error of $16.4 \%$ and a correlation coefficient of $94 \%$ for the testing stations.

Kumar et al. (2015) have studied various models based on regression as well as artificial neural networks to estimate the monthly average global solar radiations. The comparison of regression and artificial neural network models, have shown that the performance values of the artificial neural network models are better than the regression models. However, their mode only estimate the monthly average global radiation and is not capable for the instantaneous estimation.

The decomposition models are also another new tool for estimating the global solar radiation, while one of the newest investigation of decomposition models in solar radiation is daily global solar radiation decomposition (CPRG) which is done by Yao et al. (2015). Their results show that the given models established in the form of a Gaussian equation are comparatively accurate. Their models are based on consideration of the solar altitude angle, the solar azimuth angle, the solar hour angle, clearness index and temperature. However, their models estimate the daily global solar radiation.

Among the attractive strategies for such works, one can mention Neuro-fuzzy system; Iqdour and Zeroual's (2007) fuzzy has been used to model daily global solar radiation in Morocco. In their research the RMSE value for training and validation were respectively 0.76 and 0.82 .

Mohammadi et al. (2015) used an intelligent optimization scheme based on the adaptive neurofuzzy inference system (ANFIS) which was applied to develop a model for estimation of daily horizontal global solar radiation using nday as the only input. In their study, long-term measured data of Tabass (Iran) was used to train and test the ANFIS model. For the ANFIS model, the mean absolute percentage error, mean absolute bias error, root mean square error and correlation coefficient were $3.9569 \%, 0.6911 \mathrm{MJ} / \mathrm{m}^{2}, 0.8917 \mathrm{MJ} / \mathrm{m}^{2}$ and 0.9908, respectively.

In Benghanem et al. (2009), ANN models have been applied in order to estimate and model the daily global solar radiation. In their research six ANN-models were used with different combination as inputs: the air temperature, relative humidity, sunshine duration and the day of year. For each model, the output was the daily global solar radiation. It was found that the model used sunshine duration and air temperature as inputs.

In Jiang (2009), ANN model with feed-forward back-propagation algorithm has been developed for estimating the monthly mean daily global solar radiation of eight typical cities in China. The results of the ANN showed a good agreement with the measured values and were superior to those of other available empirical models.

The above-mentioned studies show the importance and effects of the models for the desired goals. However, all the above studies, either focuses on 


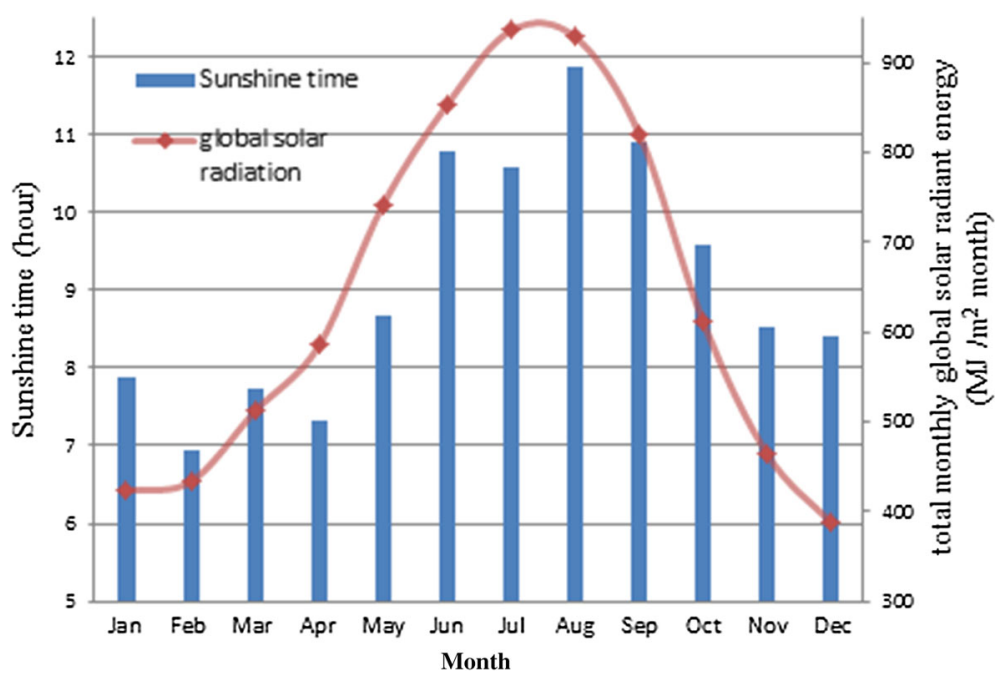

Figure 1. Total monthly global solar radiant energy $\left(\mathrm{MJ} / \mathrm{m}^{2}\right.$ month) received on the horizontal surface during sunny hours of the months in Rafsanjan in 2014.

the daily or monthly global solar radiation or 'in some' cases the hourly global solar radiation in a particular region of investigations. The momentary estimation of the global solar radiation, with a precise prediction is very rare, particularly, for arid and semi-arid regions, where the number of solar observation sites is poor. If the amount of the radiation is known instantaneously, it greatly helps the decisions and applications in various engineering fields.

In this study, two intelligent models have been done by fuzzy systems and neural networks, to estimate the instantaneous global solar radiation precisely and both models have been tested against real solar observations of six cities in semi-arid regions of Iran. Our neural network is based on MLP model, which according to our applications, performs better than $\mathrm{RBF}$ (Mishra et al. 2008).

The availability of meteorological parameters, to use as the input of radiation models, is the important key to choose the proper radiation models at any location. Among all such meteorological parameters, cloud cover and bright sunshine hours are the most widely and commonly used ones to predict daily global solar radiation and its components at any location of interest. In the current models, since the momentary global solar radiation is the output, the inputs of our model are considered as date, ambient temperature, cloud cover and bright sunshine hours.

The overall objective of the models can be summarized as follows:
- Obtaining the acceptable models with fuzzy systems and neural networks specifically for Rafsanjan (a typical semi-arid city of Iran).

- Designing the models for different functional parameters.

- Using the designed models for non-power and solar power plants in semi-arid cities of Iran.

- Testing the models against real solar observations of six cities in semi-arid regions of Iran.

In this paper, first the area under study is reviewed, then fuzzy, neural network systems and statistical indicators are studied. In the fifth section, the modelling results are shown and at the end the conclusions are mentioned.

\section{Study area}

To calculate and model the momentary radiation for semi-arid regions of Iran, the data of meteorological stations of Rafsanjan, locating in $55^{\circ} \mathrm{N}$ longitude, latitude $30.2^{\circ} \mathrm{E}$ and height $1469 \mathrm{~m}$ asl, has been used as the input of the radiation models. According to the meteorological data of Iran, the yearly average value of the global radiation of Rafsanjan is about $7692 \mathrm{MJ} / \mathrm{m}^{2}$ year or $641 \mathrm{MJ} / \mathrm{m}^{2}$ month or equivalently have $5.93 \mathrm{kWh} / \mathrm{m}^{2}$ day. Figure 1 shows the average annual sunshine hours of Rafsanjan which is more than $3360 \mathrm{hrs}$ a year. This figure shows the huge potential of solar energy in such regions. After training the models, they have been tested with the data of meteorological stations of six other cities around the Loot Desert 
of Iran, which has semi-arid climatic conditions with Rafsanjan.

\section{Methodology}

\subsection{Fuzzy systems}

In recent years, intelligent systems have been successfully used in detecting projects. One of the main advantages of intelligent systems is their ability to detect imprecise patterns.

Fuzzy logic (Wang et al. 2007), firstly developed by Lotfi Zadeh, is a new technology compared to the conventional techniques, and is used for designing and modelling the complex systems. Processing stage, which is also known as an inference engine operates as a map between input (antecedent part) and output (consequent part) statements based on a set of fuzzy rules.

Depending on the structure of the consequent part, there are two important classes of fuzzy systems. The fuzzy logic models are the first class at which the antecedent and the consequent parts are linguistic expressions. Takagi-Sugeno fuzzy models (Takagi and Sugeno 1985) are the second class and here the consequent part is a mathematical function, while the antecedent part is a linguistic expression.

\subsection{Neural network}

Artificial neural networks have been used widely in many application areas. Most applications use a feed-forward neural network (FFNN) with the back-propagation (BP) training algorithm. There are numerous variants of the classical $\mathrm{BP}$ algorithm and other training algorithms. All these training algorithms assume a fixed ANN architecture and during training, they change the weights to obtain a satisfactory mapping of the data. The main advantage of the feed-forward neural networks is that they do not require a userspecified problem solving algorithm (as is the case with classic programming), instead they 'learn' from examples, much like human beings. Another advantage is that they have inherent generalization ability. This means that they can identify and respond to patterns which are similar but not identical to the ones with which they have been trained. On the other hand, the development of a feed-forward ANN-model also poses certain problems, the most important being that there is no prior guarantee that the model will perform well for the problem at hand (Benghanem et al. 2009).

Fuzzy systems have a series of rules that are stored in its knowledge base, while ANNs are inspired by biological neural networks function and how they work. In fact the mathematical model is used for fast and accurate processing of information. Neural networks are being developed in the analysis and structural developments as well as in the hardware implementation of quantitative and qualitative growth and development (Müller et al. 1995).

Normalizing the vector components of the input and output is done in such a way that all the components are in the range $[0-1]$. In this study, the normalized input and output of the equation (1) has been used.

$$
I_{\text {norm }}=\frac{I-I_{\min }}{I_{\max }-I_{\min }} .
$$

\section{Statistical indicators}

A statistical analysis involving root mean square error (RMSE), mean bias error (MBE) and absolute fraction of variance $\left(R^{2}\right)$, is conducted to evaluate the performance accuracy of the developed models and to verify the performance trend in the models. RMSE provides information on the short-term performance, which is a measure of the variation of estimated values around the measured data. The lower the RMSE, the more accurate is the estimation. MBE is an indication of the average deviation of the estimated values from the corresponding measured data and can provide information on long-term performance of the models; the lower MBE the better the model is (Khademi et al. 2013).

Jacovides showed that use of indicators RMSE and MBE alone causes errors in the model. Therefore, it is recommended that besides these two indicators, the criterion 't-test' is used which compares the actual difference between two means in relation to the variation in the data. In other words, 't-test' indicates the significance of the difference of means with the help of RMSE and MBE (Jacovides and Kontoyiannis 1995). The expressions for the afore-mentioned statistical parameters are: 


$$
\begin{aligned}
\mathrm{RMSE} & =\sqrt{\frac{\sum_{1}^{n}\left(P_{i}-O_{i}\right)^{2}}{n}}, \\
\mathrm{MBE} & =\frac{\sum_{1}^{n}\left(P_{i}-O_{i}\right)}{n}, \\
\text { t-test } & =\sqrt{\frac{(n-1) \mathrm{MBE}^{2}}{\mathrm{RMSE}^{2}-\mathrm{MBE}^{2}}} .
\end{aligned}
$$

The lesser the RMSE value, the more accurate is the model. If the MBE is positive, the value estimated from the measured value is higher, and if MBE is negative, the measured value is less than one in the estimation.

The variability of 't-test', is large, since it is affected by the variations in both mean and standard deviation. The t-test variability decreases with an increase in the sample size because S (standard deviation) is established on the basis of more information (Jacovides and Kontoyiannis 1995). In the above equations, $P$ is the estimated amount of solar radiation, $O$ is the measured solar radiation and $n$ is the number of observations.

\section{Modelling and the results}

The cloud cover, cloud type and cloud height are measured at synoptic stations. The cloud cover parameter is generally expressed in eight units. According to the amount of the cloud present in the sky, it is categorized into $0,1 / 8, \ldots, 8 / 8$ for complete cloud cover. In the current investigation, the real-time input fuzzy and neural network models have been considered as follows: the number of days in the year, duration of data measurement, ambient temperature and cloud cover. These input variables are selected through the sensitivity analysis and the availability of the measurements of the parameters. While training a network, the effect that each of the network inputs on the network output is studied. This provides a feedback as to which input parameters are the most significant. Based on this feedback, it may be decided to prune the input space by removing the significant parameters. This also reduces the size of the network, which in turn reduces the network complexity and the training time. The sensitivity analysis is carried out by removing each of the parameters in turn from the input parameters used on ANN and fuzzy models and then comparing the performance statistics. The greater the effect observed in the output, the greater is the sensitivity of that particular input parameter (Bonakdari et al. 2015; Kyada and Pravendra 2015).

All measurements have been recorded once in every $10 \mathrm{~min}$. The measurement of the cloud cover
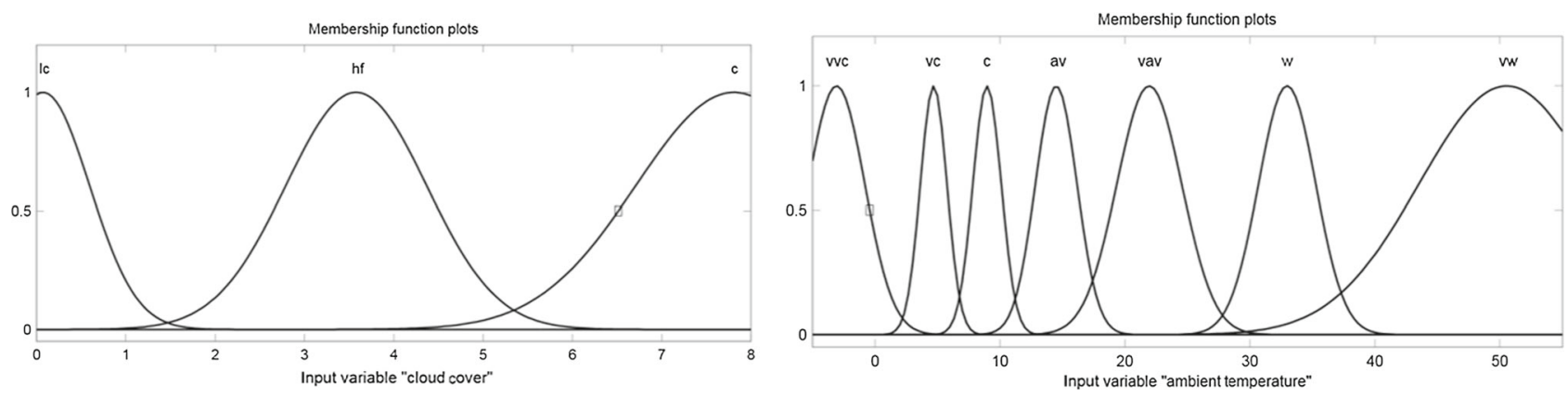

Figure 2. Membership functions of the inputs, cloud cover and ambient temperature.
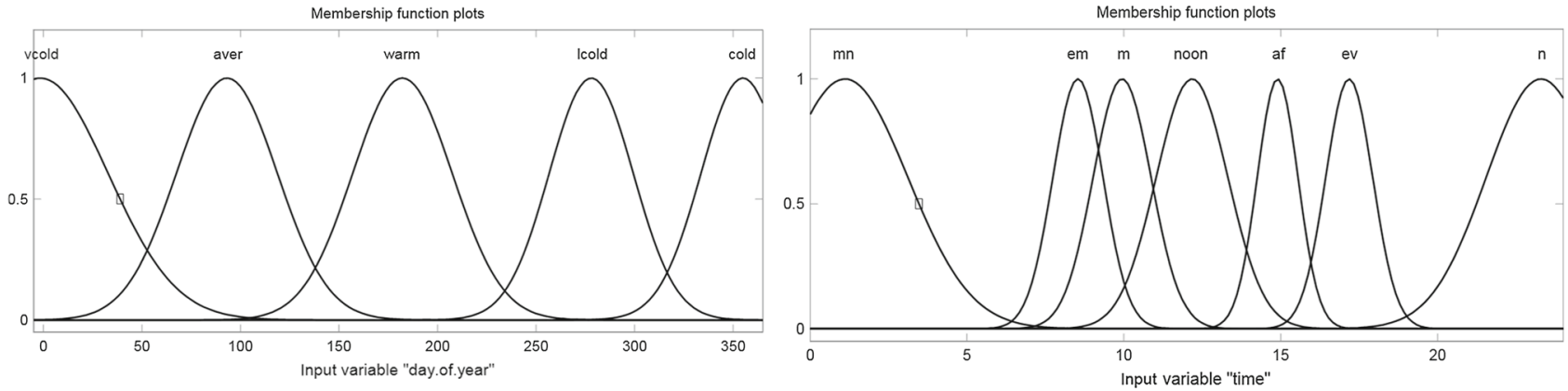

Figure 3. Membership functions of the inputs, number of days of the year and time of the day. 


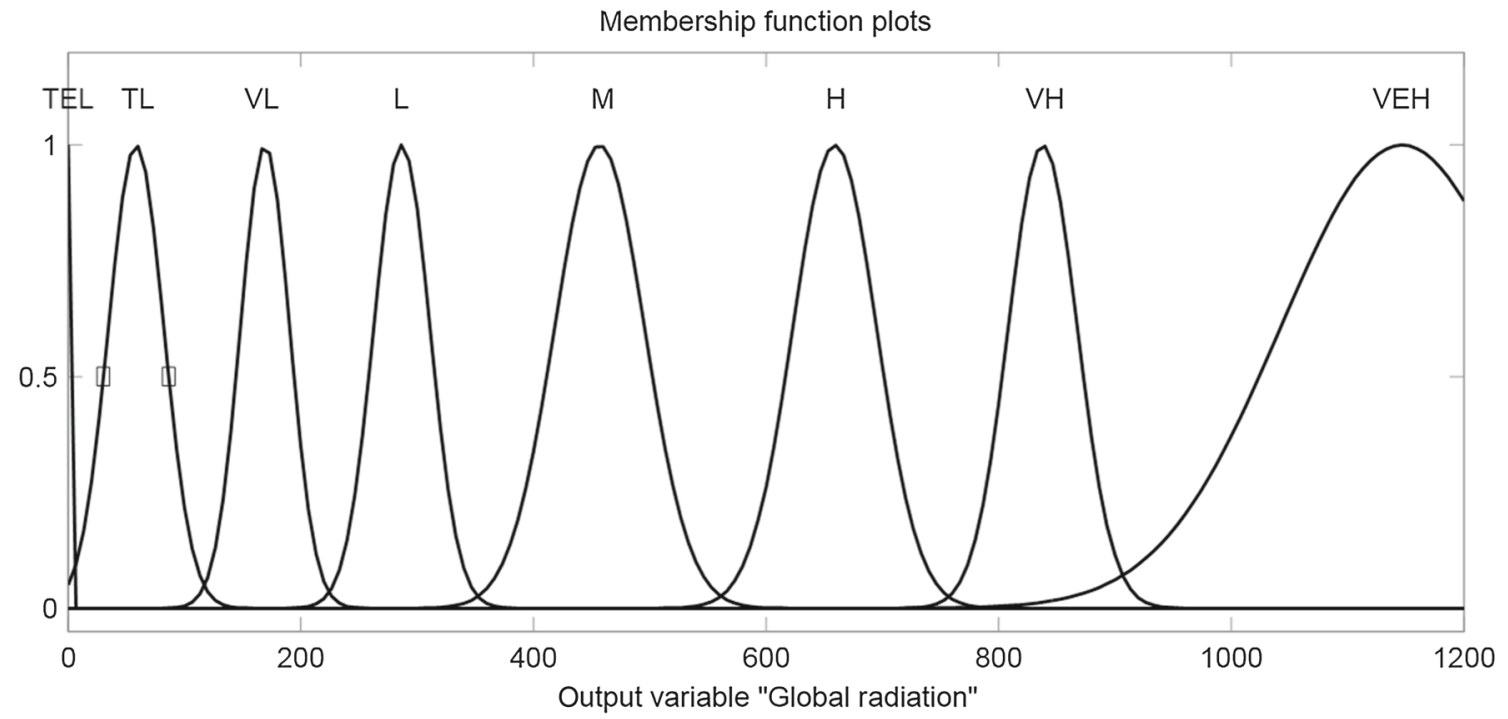

Figure 4. Membership functions of the output and global solar radiation.

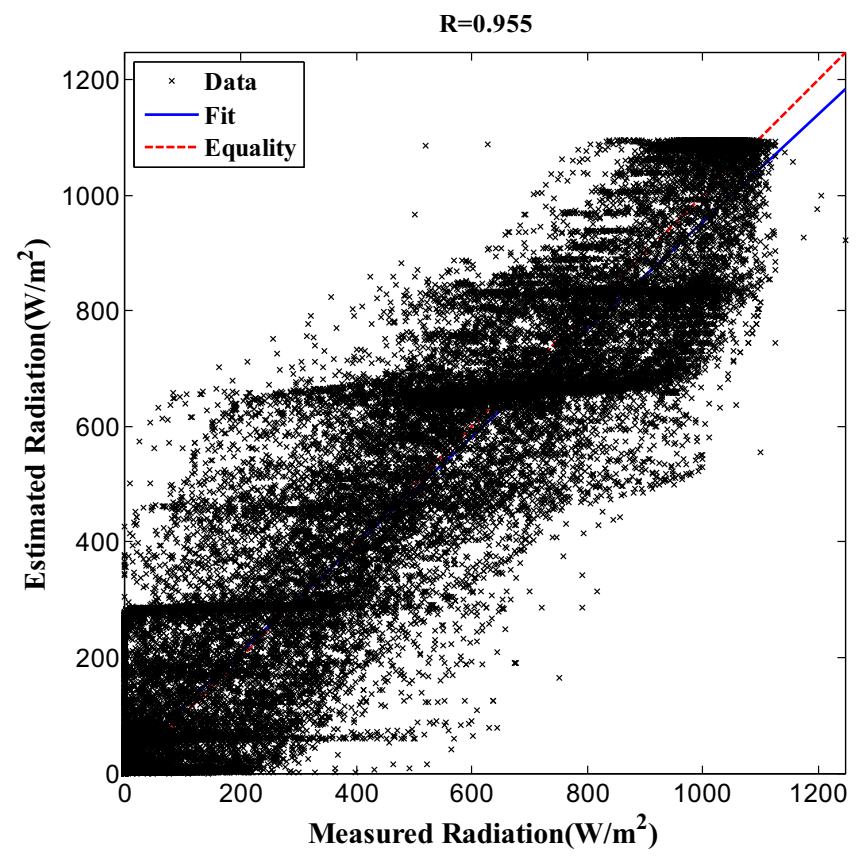

Figure 5. The scatter plot of global solar radiation measurement and estimation by fuzzy modelling in Rafsanjan.

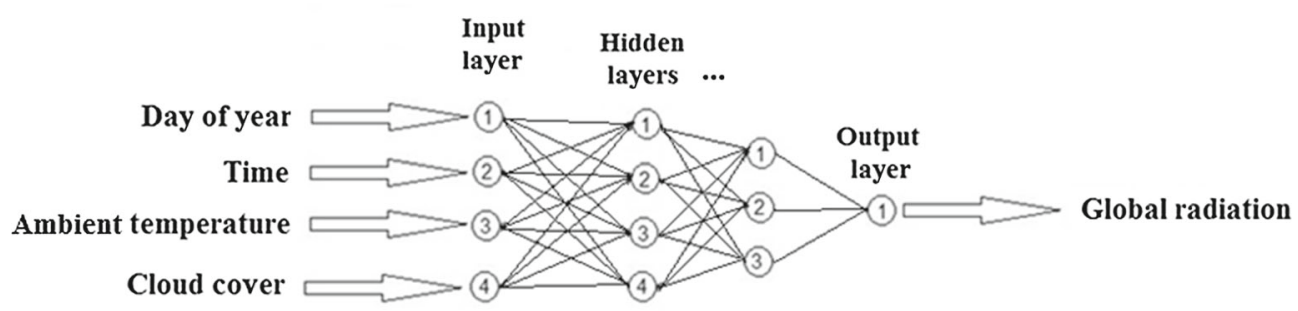

Figure 6. Inputs and output of the neural network. 


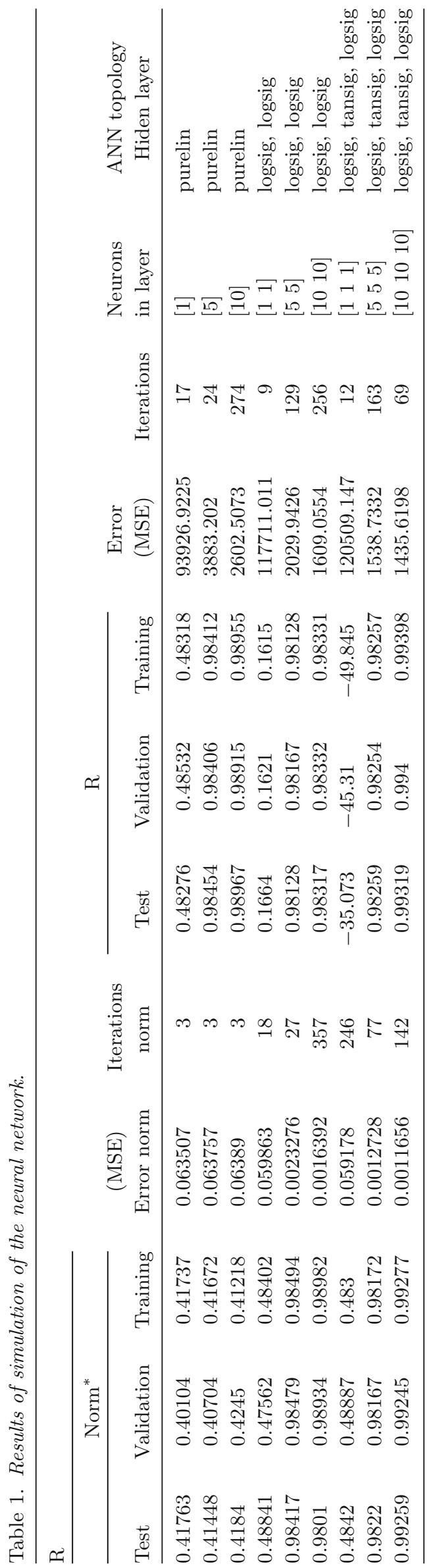

parameter has been estimated with the results of sunshine recorder papers; the given results showed a good agreement with the empirical data of cloud cover obtained at synoptic station.

Figures 2-4 illustrate membership functions of the inputs and output of the fuzzy mode. The input cloud cover has been falsified as c, hf and lc which respectively presented complete cloud cover, half cloud cover and low cloud cover. In the same way, the input ambient temperature fuzzified in the range of ambient temperature as shown in figure 3.

The input day number, which indicates the day of the year (figure 3) has been fuzzified as vc (very cold), a (average), w (warm), lc (low cold), c (cold), while for the inputs a similar procedure is considered; the time of day (figure 3 ) fuzzified as mn (mid-night), em (early morning), m (morning), noon, af (afternoon), ev (evening), n (night).

The output global radiation (figure 4) fuzzified as TEL (too extreme low: $\mathrm{G}<20 \mathrm{w} / \mathrm{m}^{2}$ ), TL (too low), VL (very low), L (low), M (medium), H (high), VH (very high), and VEH (very extreme high).

For determining rule-based system approaches, trial and error method has been applied, also to improve the output, lower MSE and higher $R$, have been selected. There are several defuzzification methods. Probably the most popular one is the defuzzification centre of gravity technique, which here, is coupled with Mamdani's inference engine and max-min method. The defuzzification centre of gravity method performs based on finding the point where a vertical line would slice the aggregate set into two equal masses. COG is the center of gravity of fuzzy sets which will be considered as the output of the fuzzy process (Chen et al. 2013).

The model is intended with 243 rules, the below items are some of them.

- If (day.of.year is vc) and (time is m) and (cloud cover is c) and (air_temperature is c) then (Global_radiation is VL).

- If (day.of.year is av) and (time is noon) and (cloud cover is hf) and (air_temperature is vc) then (Global_radiation is L).

The scatter plot of global solar radiation measurement and estimation with fuzzy modelling in Rafsanjan is presented in figure 5 as it is obvious that the results of fuzzy method are matched well with the ones of measurement. Figure 6 indicates the inputs used in the neural network.

In this section, the neural network with different layers, different number of neurons and 


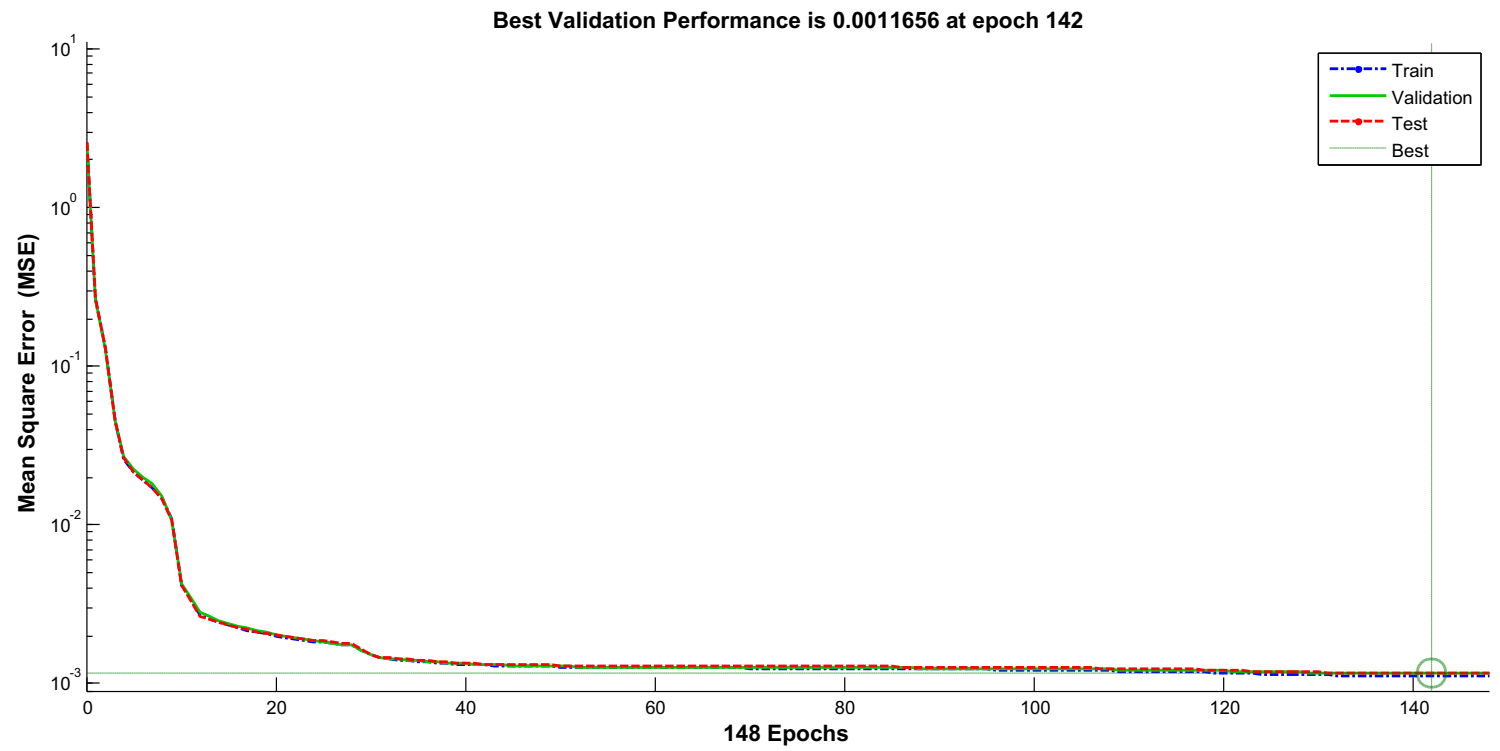

Figure 7. Diagram of the neural network convergence and achievement of the minimum MSE (normalized data).
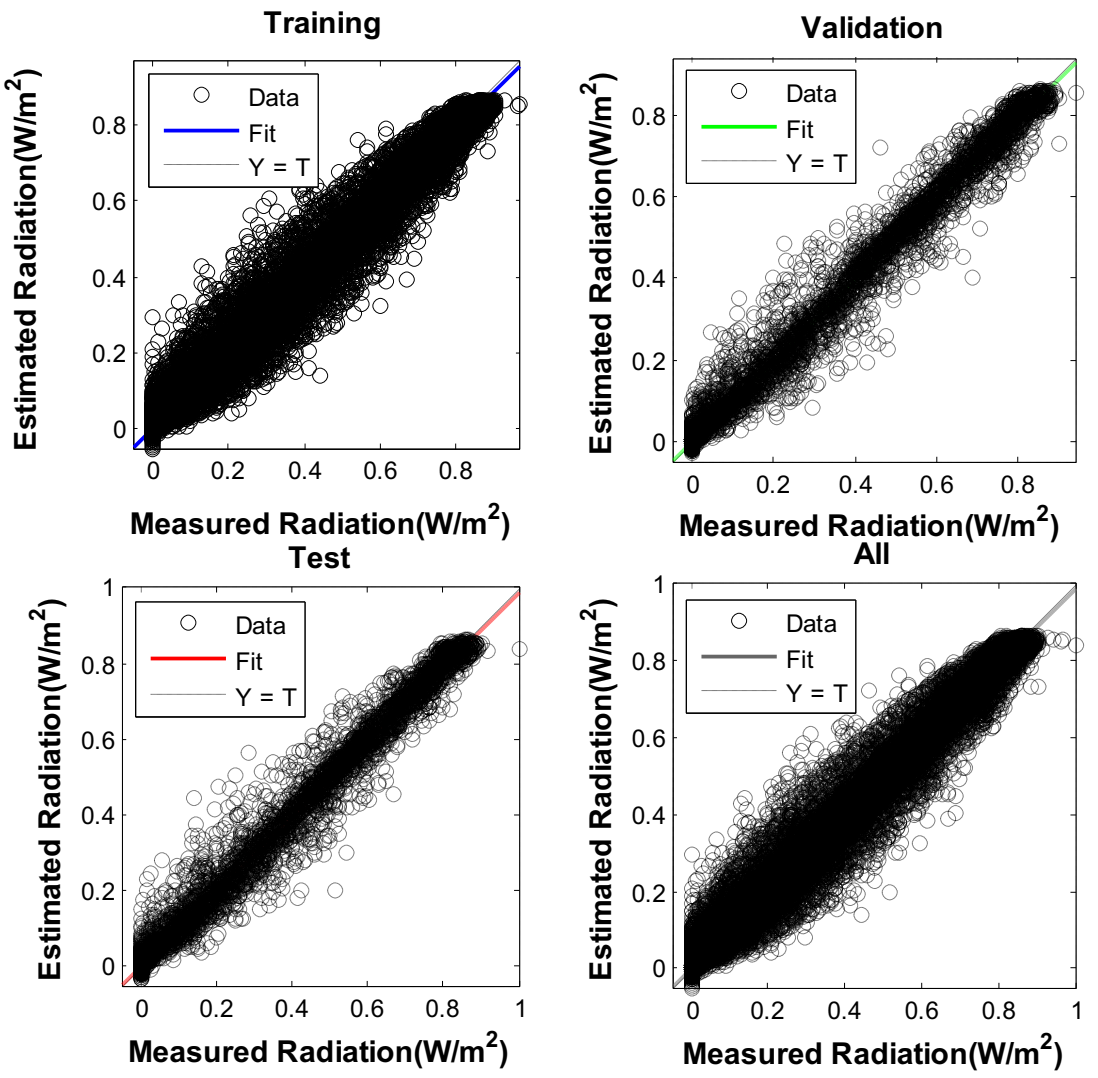

Figure 8. The actual radiation vs. estimated counterparts from the neural network (normalized data).

different functions are investigated. Table 1 shows the results of both conditions; with and without the normalized data. This model has been used in the Trainlm training function. For determining the function and the number of neurons and hiden layers, trial and error method has been applied. This method which is characterised by repeated varied attempts are continued until success, or until the agent stops trying.

Also to improve the output, lower MSE and higher $R$, have been selected. According to the principles of neural network, when $R$ increases 


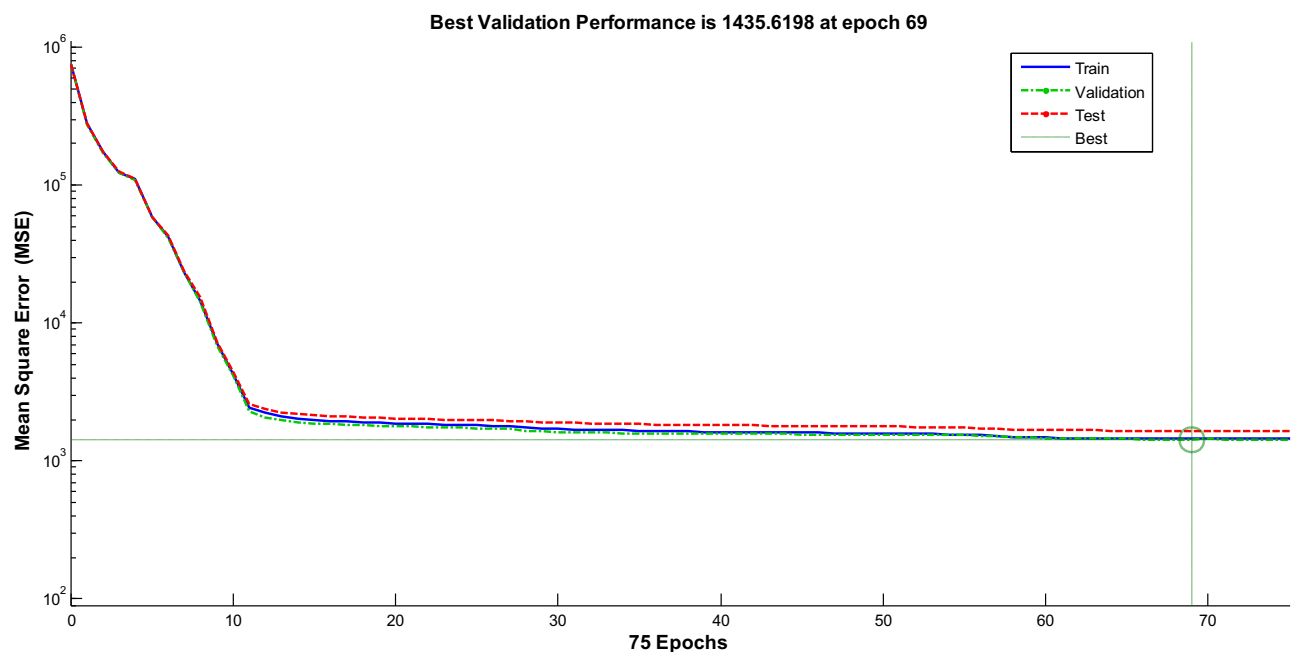

Figure 9. Diagram of the neural network convergence and its achievement to the minimums.
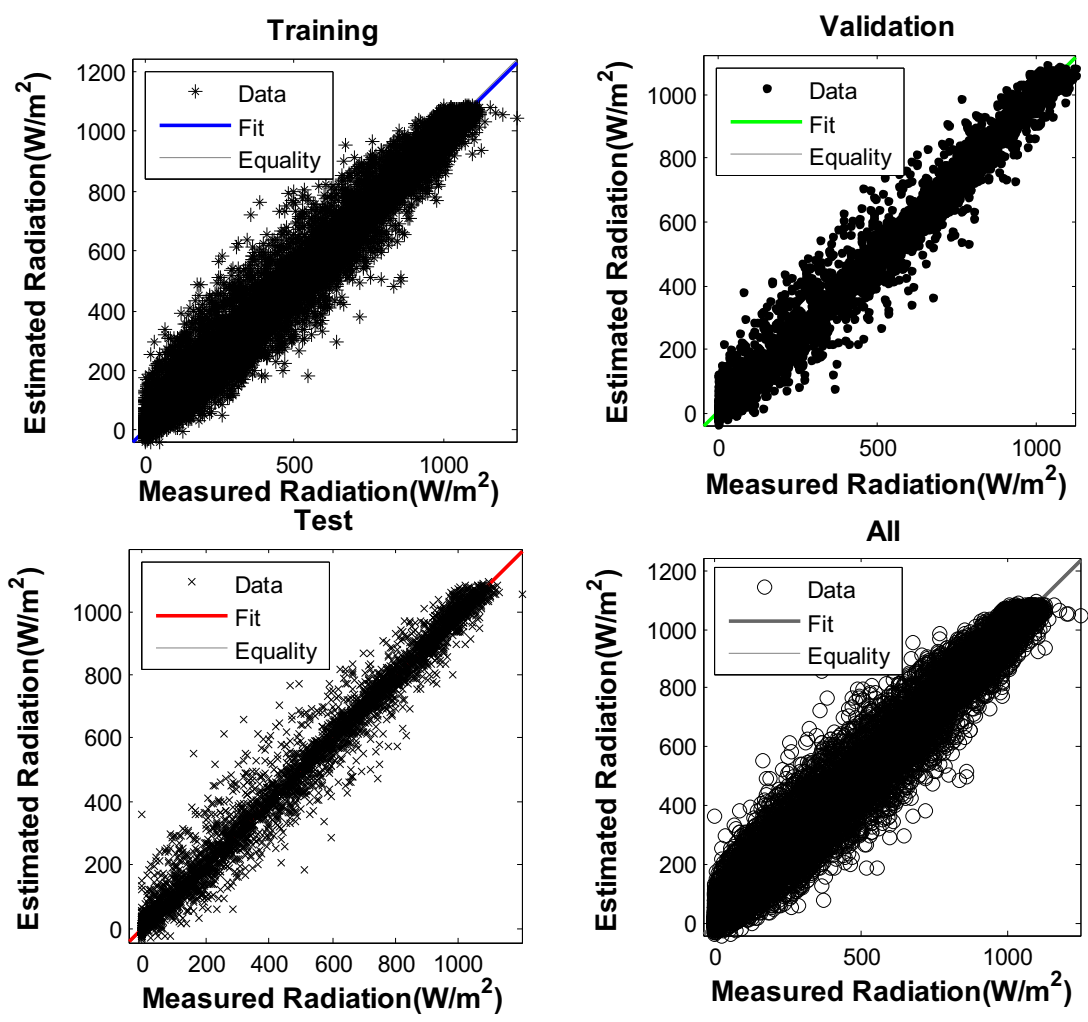

Figure 10. The actual radiation vs. estimated counterparts from the neural network.

Table 2. Evaluation of the fuzzy model and the neural network model by statistical indicators for a year.

\begin{tabular}{llll}
\hline t-test & $\begin{array}{l}\text { MBE } \\
\left(\mathrm{W} / \mathrm{m}^{2}\right)\end{array}$ & $\begin{array}{l}\text { RMSE } \\
\left(\mathrm{W} / \mathrm{m}^{2}\right)\end{array}$ & \\
\hline 9.1318 & 4.1169 & 103.4367 & Fuzzy \\
5.41 & 3.08 & 85.46 & ANN \\
\hline
\end{tabular}

the given model goes to the target, and when $R$ approaches to 1 , the output of the model is reaching perfectly similar to the real system.
In this simulation, $70 \%$ of the data is used for training the neural network, $15 \%$ for validation and $15 \%$ for testing systems. The neural network has been designed with excitation function, including the logsig, tansig, logsig as hidden layers, neurons [10 10 10] and output function (Purelin).

Figure 7 illustrates the convergence of the neural network and the minimum mean square error (MSE) for the normalized data. The non-normalized data are shown in figure 9. As it is obvious, the 
Table 3. Evaluation of the fuzzy model and the neural network model by statistical indicators for each month.

\begin{tabular}{|c|c|c|c|c|c|c|}
\hline \multicolumn{2}{|l|}{ t-test } & \multicolumn{2}{|c|}{$\operatorname{MBE}\left(\mathrm{W} / \mathrm{m}^{2}\right)$} & \multicolumn{2}{|c|}{$\operatorname{RMSE}\left(\mathrm{W} / \mathrm{m}^{2}\right)$} & \multirow[b]{2}{*}{ Month } \\
\hline ANN & Fuzzy & ANN & Fuzzy & $\mathrm{ANN}$ & Fuzzy & \\
\hline 0.0268 & 0.079 & 0.49 & 0.9944 & 77.11 & 82.0414 & January \\
\hline 1.4406 & 1.6154 & 0.64 & 0.807 & 57.45 & 83.2593 & February \\
\hline 2.4707 & 4.3035 & 3.3008 & 5.8534 & 66.34 & 93.9229 & March \\
\hline 0.802 & 2.9291 & -3.6802 & -5.0102 & 83.44 & 108.6994 & April \\
\hline 5.4111 & 6.6901 & -8.3511 & -10.1255 & 57.602 & 101.605 & May \\
\hline 3.5436 & 4.6317 & 7.8428 & 8.3516 & 75.47 & 118.7793 & June \\
\hline 1.1542 & 2.6117 & 3.067 & 4.7655 & 49.51 & 121.9779 & July \\
\hline 7.2627 & 8.6152 & 10.3453 & 13.6378 & 68.82 & 106.617 & August \\
\hline 2.9351 & 3.0837 & -4.2565 & -5.5535 & 87.66 & 116.4839 & September \\
\hline 2.9666 & 4.2018 & 9.3294 & 11.9401 & 69.48 & 110.3353 & October \\
\hline 7.0869 & 8.129 & 8.3227 & 12.9208 & 64.04 & 106.9569 & November \\
\hline 5.4576 & 9.2109 & -9.1346 & -10.9188 & 51.82 & 80.109 & December \\
\hline
\end{tabular}

neural network is able to achieve the minimum MSE with the least expected iteration. Figures 8 (normalized) and 10 show the relationship between the actual radiation and the estimated radiation obtained by the neural network. In these figures, the training data, validation and testing are shown.

In the following section, the fuzzy model and neural network model have been evaluated with error indicators. Table 2 shows the values of the indicators for both models during a year; both neural networks and fuzzy models yield good performance in comparison with the experimental results. In table 3 , the results of both models for each month are shown.

Figures 11-14 show the global solar radiation of the fuzzy model, the neural network model and measured values for a day of each month.

The obtained results indicate that both models can be used for predicting instantaneous global solar radiation based on climatological parameters in Rafsanjan, while ANN model performs more accurate estimation than the fuzzy model for the instantaneous global solar radiation. Hence, these models can be used for the prediction of the instantaneous global solar radiation at any place with similar semi-arid climatological parameters of Iran.

For validation of the models, the given models have been tested for six other cities (Yazd, Qom and Birjand, Zahedan, Shiraz, Sabzevar), around the desert of Loot of Iran (figure 15). It should mention that about $70 \%$ of Iran is located in arid and semi-arid regions, which are below the validations of different cities around the given area (table 4).

In order to compare predicted values of instantaneous global solar radiation with real data of testing stations, the error indicators of the fuzzy model and neural network model are tabulated in table 5, which shows the comparison of a month of each season. As it can be seen from the results, predicted values of both methods have fairly close agreement with the corresponding actual measurements. The results render both models as a promising alternative method for estimating the instantaneous global solar radiation as a function of geographical and meteorological parameters.

In figures 16-18, the model has been applied to a random day of all other cities.

\section{Conclusions}

In the present study, artificial neural network and fuzzy based models were designed and developed to estimate the global solar radiation. The main originality of these models is estimated of the instantaneous solar radiation with the use of momentary meteorological data as inputs to overcome the lack of measured database. The models, firstly, were developed and applied to Rafsanjan $(55 \mathrm{~N}, 30.2 \mathrm{E})$, located in the southeast of Iran, which has a typical climate conditions of semi-arid regions. 

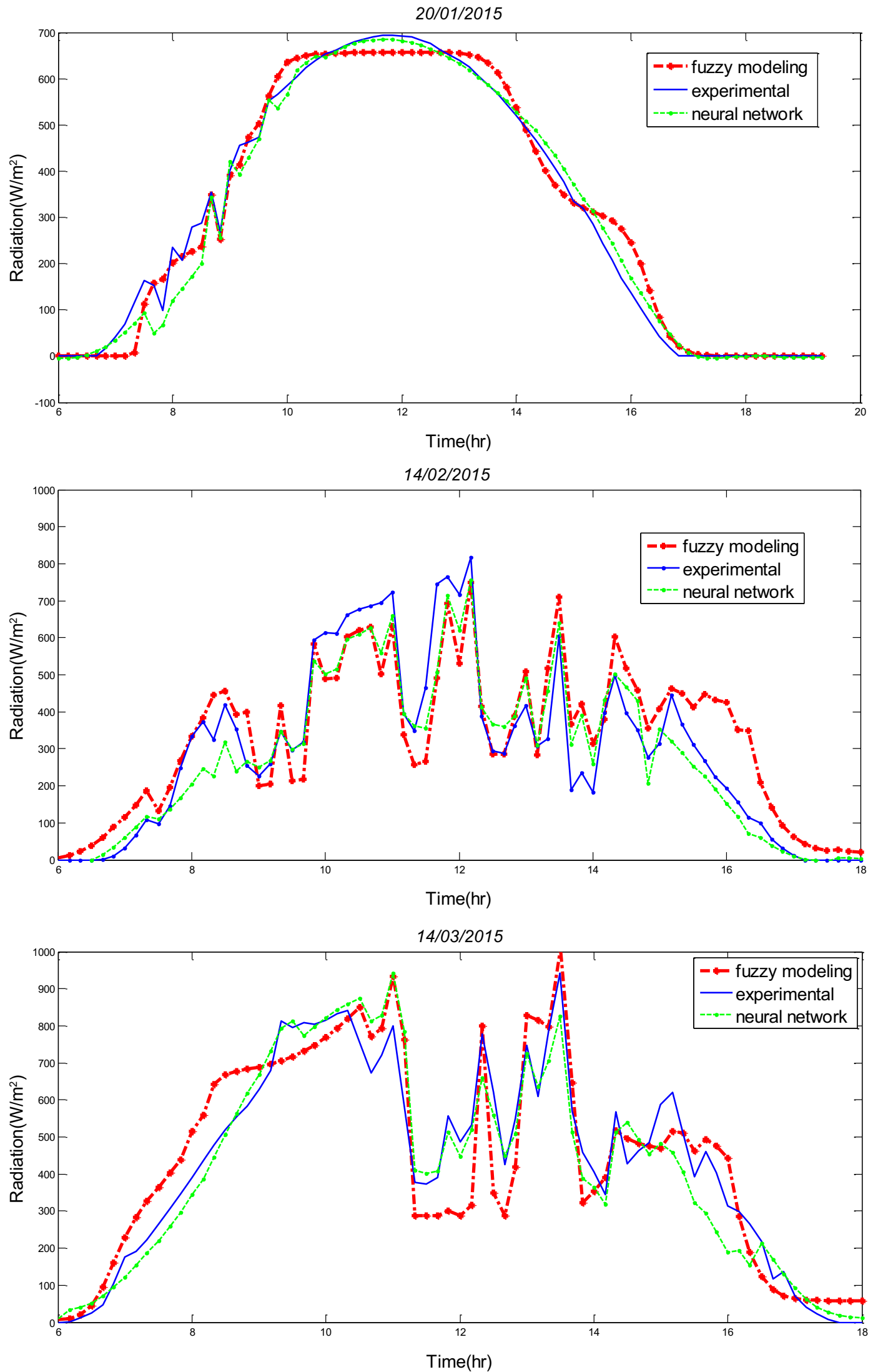

Figure 11. Comparison of the global solar radiation obtained by the fuzzy model, the neural network model and measured values for a day of the first three months. 

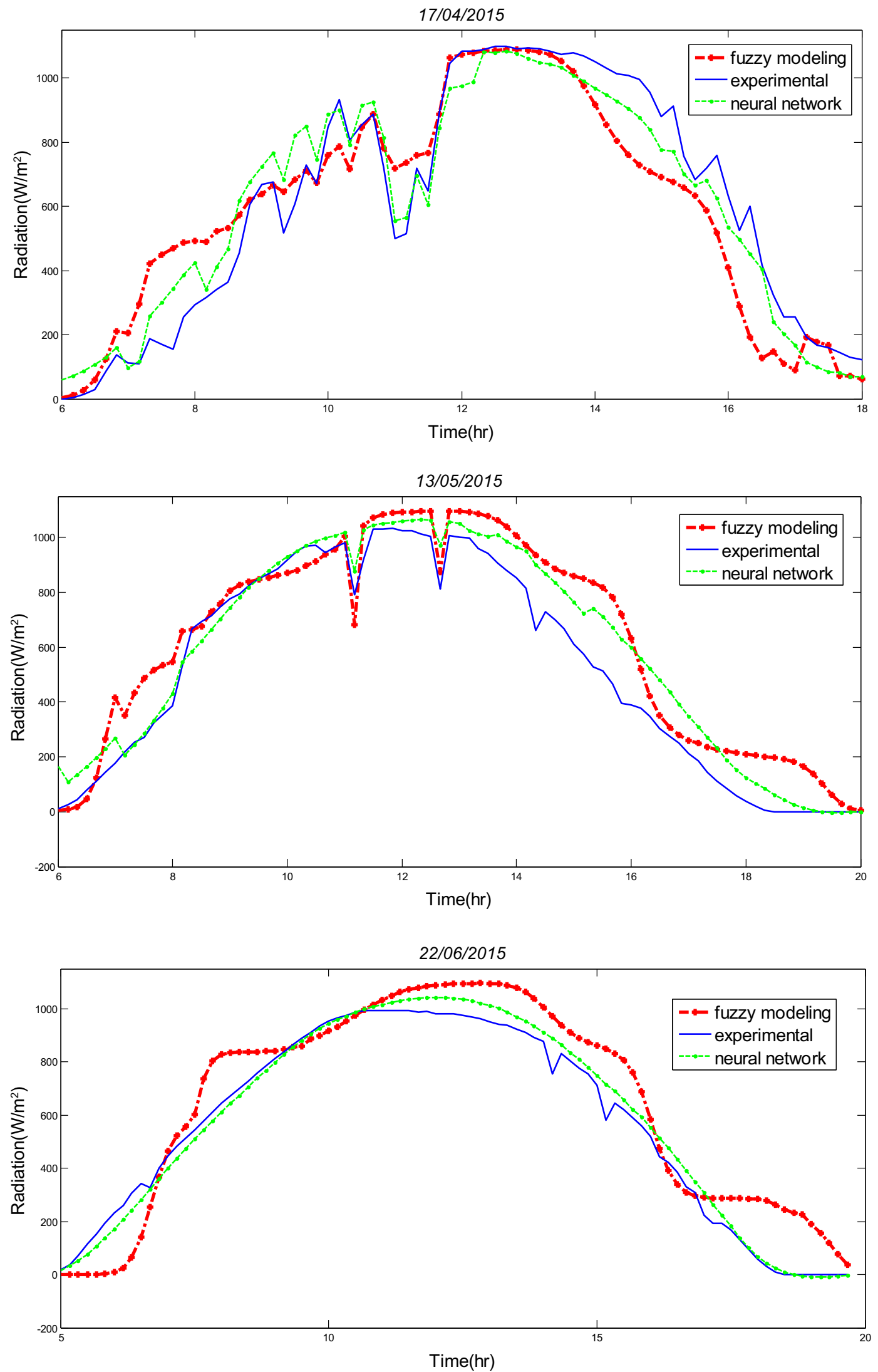

Figure 12. Comparison of the global solar radiation obtained by the fuzzy model, the neural network model and measured values for a day of the second three months. 

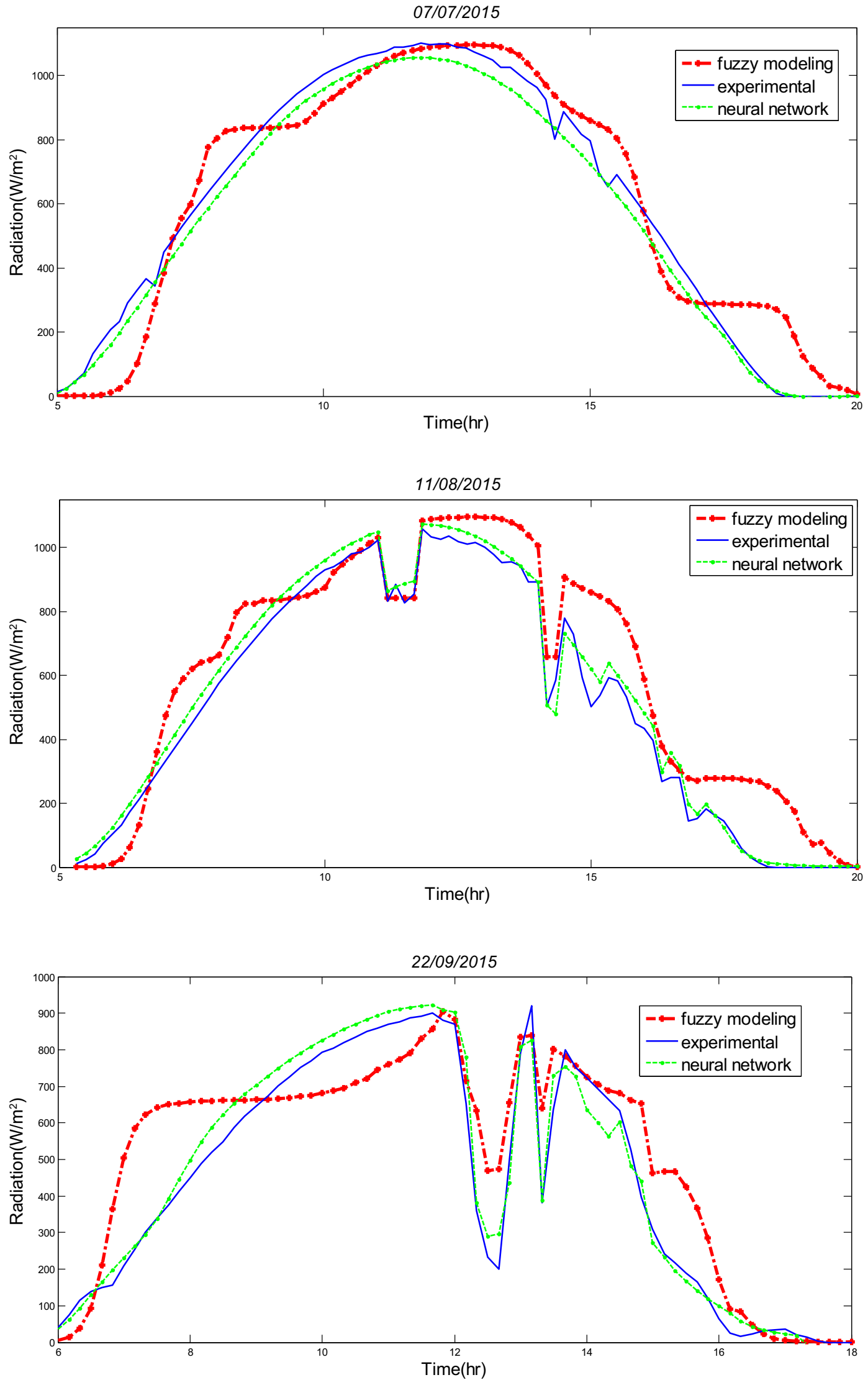

Figure 13. Comparison of the global solar radiation obtained by the fuzzy model, the neural network model and measured values for a day of the third three months. 

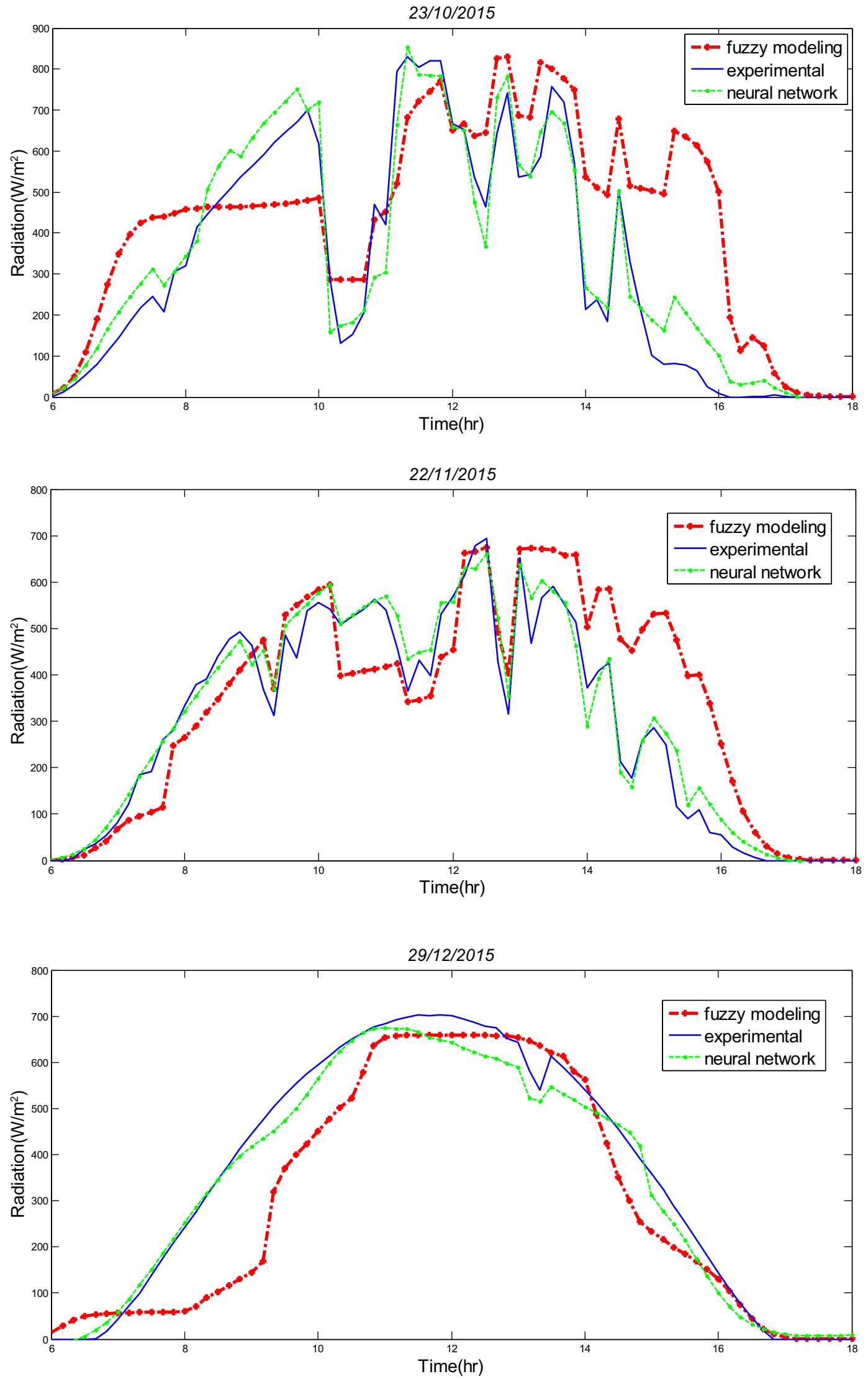

Figure 14. Comparison of the global solar radiation obtained by the fuzzy model, the neural network model and measured values for a day of the fourth three months. 


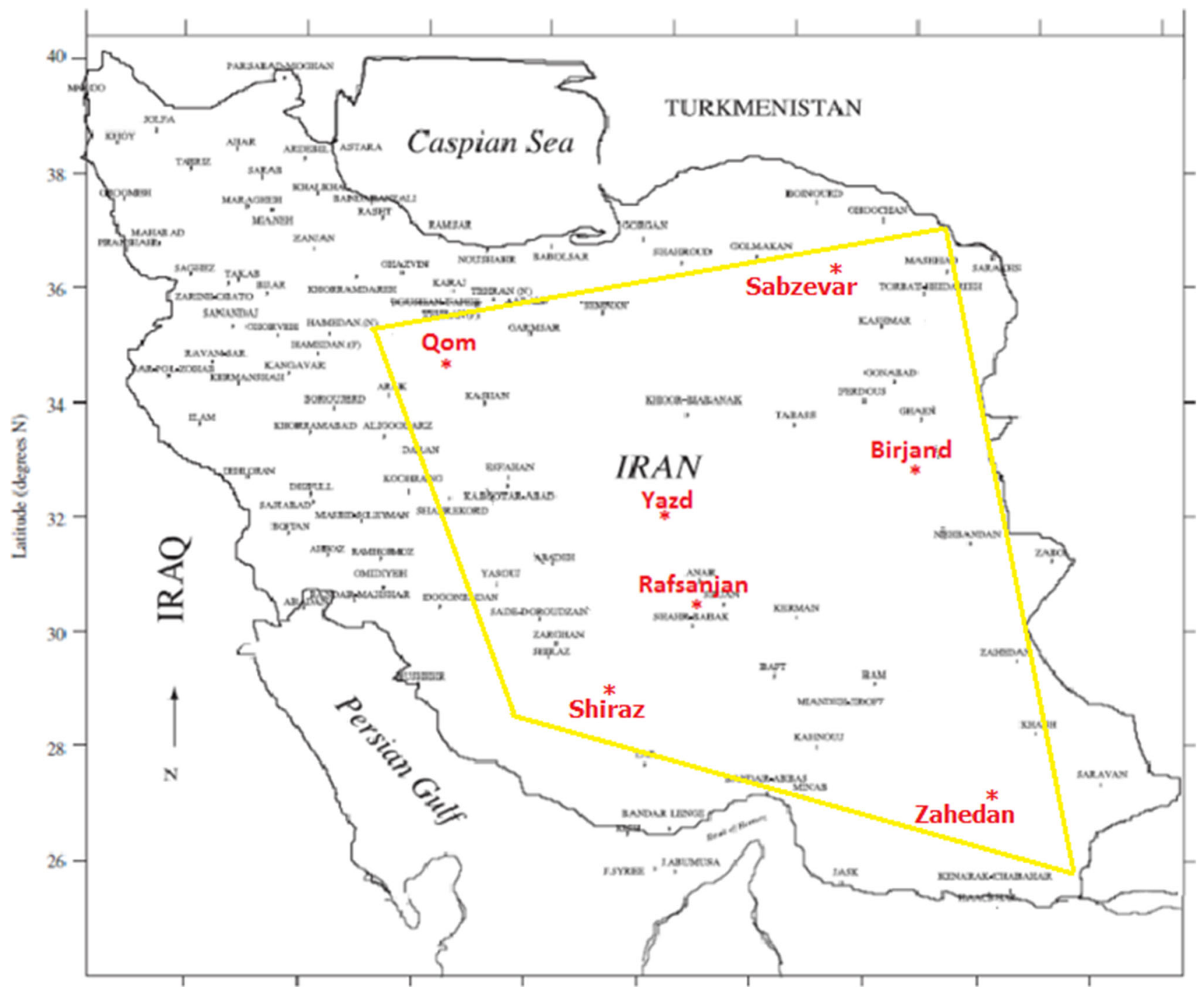

Figure 15. The location of the tested cities.

Table 4. The indicators of the fuzzy model and neural network model during a year.

\begin{tabular}{|c|c|c|c|c|c|c|c|c|}
\hline \multirow[b]{2}{*}{. } & \multirow[b]{2}{*}{ Lat. (deg) } & \multirow[b]{2}{*}{ Long. (deg) } & \multicolumn{2}{|c|}{$\operatorname{RMSE}\left(\mathrm{W} / \mathrm{m}^{2}\right)$} & \multicolumn{2}{|c|}{$\operatorname{MBE}\left(\mathrm{W} / \mathrm{m}^{2}\right)$} & \multicolumn{2}{|c|}{ t-test } \\
\hline & & & $\mathrm{ANN}$ & Fuzzy & ANN & Fuzzy & ANN & Fuzzy \\
\hline Yazd & 31.89 & 54.35 & 39.9 & 113.6 & 3.012 & 5.1 & 6.0362 & 8.73 \\
\hline Qom & 34.5 & 50.9 & 66.3 & 117.4 & 5.037 & 7.1 & 8.262 & 10.53 \\
\hline Birjand & 32.87 & 59.22 & 56.6 & 132.3 & 2.0274 & 5.6 & 6.592 & 9.436 \\
\hline Zahedan & 29.3 & 60.5 & 44.3 & 103.2 & 3.02 & 6.3 & 5.022 & 7.14 \\
\hline Shiraz & 29.39 & 52.35 & 48.9 & 115.6 & 2.045 & 4.2 & 6.075 & 9.44 \\
\hline Sabzevar & 36.15 & 57.4 & 52.3 & 125.3 & 4.0251 & 5.3 & 7.72 & 9.6 \\
\hline
\end{tabular}

Validating tests have been performed with the help of data measured over one year for the cited location, which showed that both techniques have fairly close agreement with the corresponding actual measurements.

However, with respect to the RMS, MBA and ttest indicators, estimated results by ANN produce smaller estimation-errors compared to fuzzy.
For validation, the given models have been tested for three other cities with similar semiarid climatic conditions; comparing the statistical parameters for artificial neural network and fuzzy based model for a month of each season proves that the models work well in terms of root mean square error (RMSE). 
Table 5. The indicators of the fuzzy model and neural network model for four months.

\begin{tabular}{|c|c|c|c|c|c|c|c|}
\hline & \multicolumn{2}{|c|}{$\operatorname{RMSE}\left(\mathrm{W} / \mathrm{m}^{2}\right)$} & \multicolumn{2}{|c|}{$\operatorname{MBE}\left(\mathrm{W} / \mathrm{m}^{2}\right)$} & \multicolumn{2}{|c|}{ t-test } \\
\hline & & ANN & Fuzzy & ANN & Fuzzy & ANN & Fuzzy \\
\hline \multirow[t]{6}{*}{ February } & Yazd & 47.8 & 93.9 & 0.36 & 0.70 & 0.73 & 0.58 \\
\hline & Qom & 63.1 & 112.2 & 0.4 & 0.62 & 3.06 & 2.43 \\
\hline & Birjand & 68.8 & 106.5 & 0.6 & 0.72 & 2.75 & 1.75 \\
\hline & Zahedan & 73.2 & 133.5 & 0.33 & 0.24 & 3.42 & 3.44 \\
\hline & Shiraz & 64.3 & 116.4 & 0.5 & 0.66 & 1.58 & 0.68 \\
\hline & Sabzevar & 78.7 & 96.5 & 0.47 & 0.53 & 0.36 & 2.11 \\
\hline \multirow[t]{6}{*}{ May } & Yazd & 58.6 & 104.6 & -4.45 & -9.3 & 0.62 & 4.21 \\
\hline & Qom & 87.7 & 118.4 & -5.85 & -11.5 & 1.73 & 8.91 \\
\hline & Birjand & 61.2 & 111.5 & -0.61 & -1.2 & 1.12 & 6.3 \\
\hline & Zahedan & 61.4 & 97.4 & -7.49 & -10.4 & 0.34 & 5.41 \\
\hline & Shiraz & 55.2 & 103.2 & -3.73 & -6.5 & 1.55 & 7.33 \\
\hline & Sabzevar & 76.7 & 111.3 & -4.26 & -8.7 & 0.66 & 6.88 \\
\hline \multirow[t]{6}{*}{ July } & Yazd & 66.5 & 123.6 & 3.07 & 4.96 & 0.26 & 1.7 \\
\hline & Qom & 89.1 & 142.7 & 5.09 & 6.2 & 3.4 & 4.53 \\
\hline & Birjand & 71.3 & 119.3 & 2.087 & 5.3 & 2.78 & 3.363 \\
\hline & Zahedan & 73.1 & 93.7 & 3.07 & 4.5 & 1.2 & 7.423 \\
\hline & Shiraz & 55.2 & 105.6 & 3.095 & 5.5 & 2.3 & 3.22 \\
\hline & Sabzevar & 65.7 & 120.7 & 5.077 & 7.8 & 1.4 & 1.19 \\
\hline \multirow[t]{6}{*}{ November } & Yazd & 55.4 & 96.6 & 2.3 & 8.6 & 6.67 & 8.34 \\
\hline & Qom & 64.2 & 133.3 & 7.2 & 13.8 & 10.88 & 13.96 \\
\hline & Birjand & 53.1 & 118.5 & 4.7 & 10.2 & 9.93 & 11.2 \\
\hline & Zahedan & 52.2 & 103.3 & 6.1 & 9.7 & 7.6 & 10.6 \\
\hline & Shiraz & 47.8 & 111.4 & 8.7 & 10.9 & 5.1 & 7.46 \\
\hline & Sabzevar & 61.2 & 121.2 & 5.32 & 8.8 & 9.2 & 3.25 \\
\hline
\end{tabular}

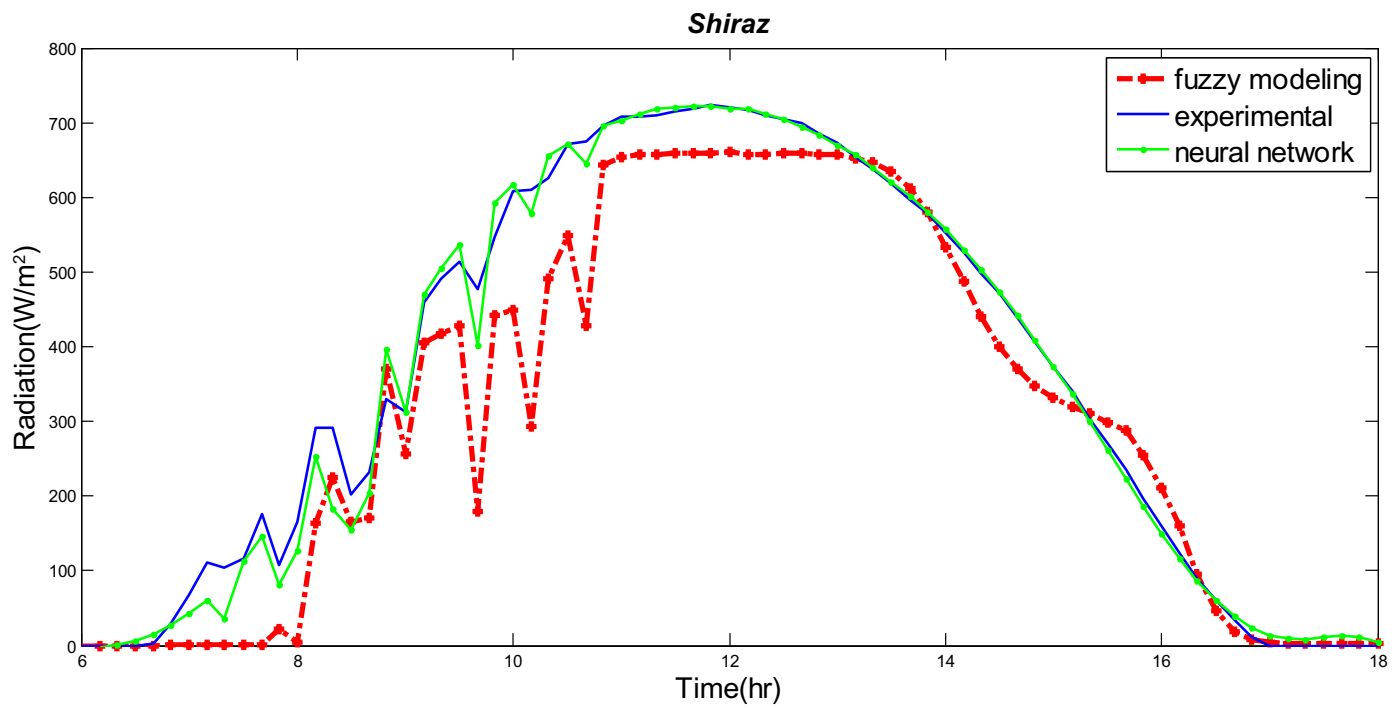

Figure 16. Comparison of the global solar radiation obtained by the fuzzy model, the neural network model and measured values for a random day in Shiraz city.

This agreement of the results indicates that both models can estimate the instantaneous global solar radiation with satisfactory accuracy. Besides, both models provide helpful information which can be used for site selection, solar map creation and solar plants, designing and planning in semi-arid geological regions around the world. 



Figure 17. Comparison of the global solar radiation obtained by the fuzzy model, the neural network model and measured values for a random day of Birjand, Qom and Zahedan cities. 

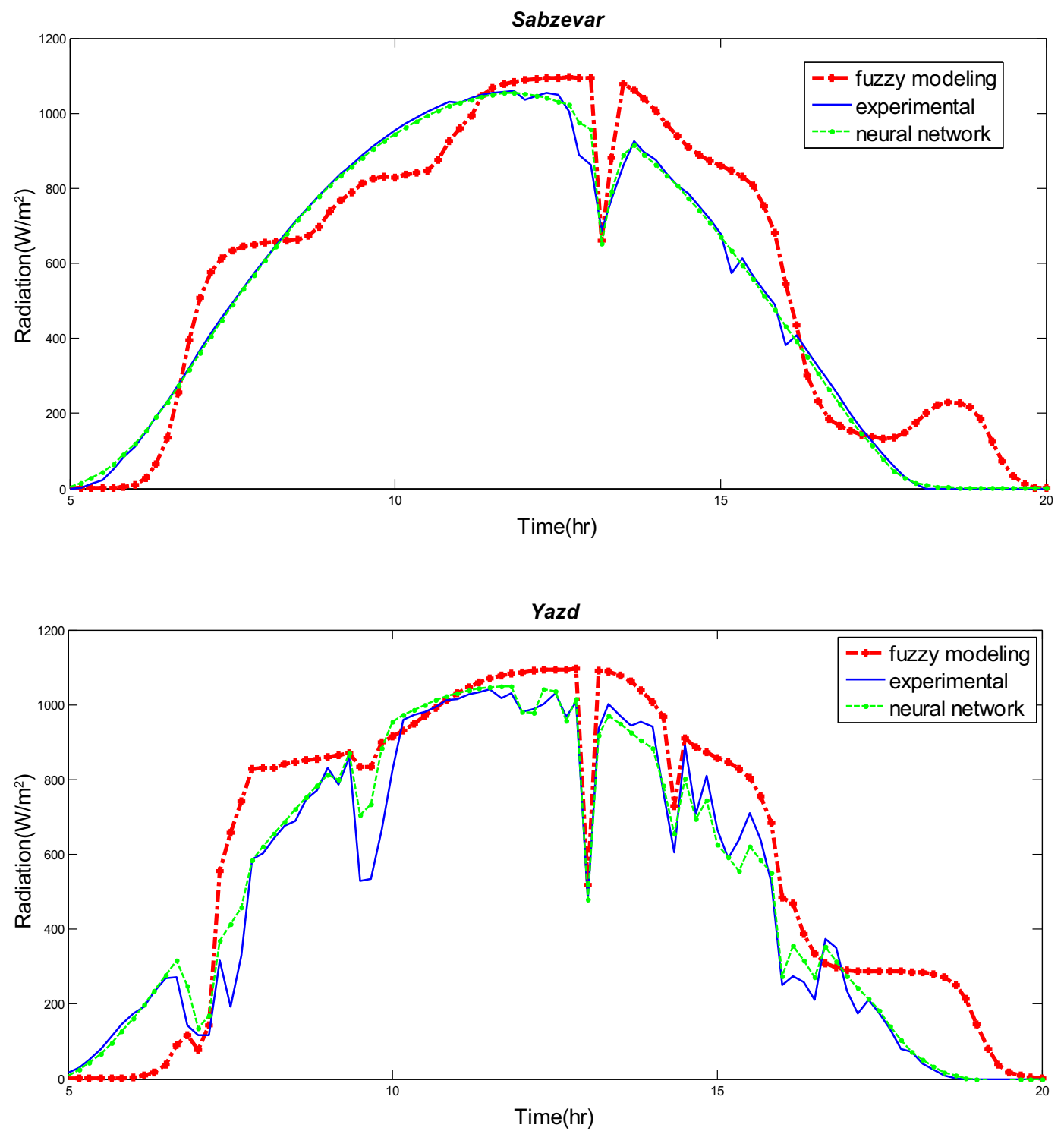

Figure 18. Comparison of the global solar radiation obtained by the fuzzy model, the neural network model and measured values for a random day in Sabzevar and Yazd cities.

The main advantage of this method is the ability to measure the instantaneous solar global radiation, with an accurate and fast processing of semiarid regions of Iran, which have been validated for all seasons and months of the year. According to the resulting model, it makes it suitable to estimate the global radiation in the semi-arid cities of Iran.

\section{Acknowledgements}

The authors would like to acknowledge the Iranian Meteorological Organization for meteorological data. The authors would like to appreciate the assessment of Mr Mohammad Bazmandegan and
Mr Mohsen Eslami (meteorological center of Rafsanjan) for providing meteorological data. Also, the authors appreciate the respected journal reviewers for their beneficial comments that promoted this research.

\section{References}

Azadeh A, Maghsoudi A and Sohrabkhani S 2009 An integrated artificial neural networks approach for predicting global radiation; Energy Convers. Manag. 50(6) 14971505.

Behrang M A, Assareh E, Ghanbarzadeh A and Noghrehabadi A R 2010 The potential of different artificial neural network (ANN) techniques in daily global solar radiation 
modeling based on meteorological data; Sol. Energy $\mathbf{8 4 ( 8 )}$ 1468-1480.

Benghanem M, Mellit A and Alamri S N 2009 ANN-based modelling and estimation of daily global solar radiation data: A case study; Energy Convers. Manag. 50(7) 1644-1655.

Bhardwaj S et al. 2013 Estimation of solar radiation using a combination of Hidden Markov Model and generalized fuzzy model; Sol. Energy 93 43-54.

Bonakdari H, Zaji A H, Shamshirband S, Hashim R and Petkovic D 2015 Sensitivity analysis of the discharge coefficient of a modified triangular side weir by adaptive neuro-fuzzy methodology; Measurement $\mathbf{7 3}$ 7481.

Chen S X, Gooi H B and Wang M Q 2013 Solar radiation forecast based on fuzzy logic and neural networks; Renew. Energy 60 195-201.

El Mghouchi Y, El Bouardi A, Choulli Z and Ajzoul T 2014 New model to estimate and evaluate the solar radiation; Int. J. Sust. Built Environ. 3(2) 225-234.

Iqdour R and Zeroual A 2007 Prediction of daily global solar radiation using fuzzy systems; J. Sust. Built Environ. 26(1) 19-29.

Jacovides C P and Kontoyiannis H 1995 Statistical procedures for the evaluation of evapotranspiration computing models; Agric. Water Manag. 27(3) 365371.

Jiang Y 2009 Computation of monthly mean daily global solar radiation in China using artificial neural networks and comparison with other empirical models; Energy 34(9) 1276-1283.

Khademi M, Jafarkazemi F, Bahramian F and Nikookar A 2013 Using neuro-fuzzy techniques in estimating monthly global solar radiation for Tehran, Iran; J. Basic Appl. Sci. Res. 3(1) 275-280.

Kumar R, Aggarwal R K and Sharma J D 2015 Comparison of regression and artificial neural network models for estimation of global solar radiations; Renew. Sustain. Energy Rev. 52 1294-1299.

Kyada P M and Pravendra K 2015 Daily rainfall forecasting using adaptive neurofuzzy inference system (ANFIS) models; Int. J. Sci. Nat. 6(3) 382-388.

Linares-Rodríguez A, Ruiz-Arias J A, Pozo-Vázquez D and Tovar-Pescador J 2011 Generation of synthetic daily global solar radiation data based on ERA-interim reanalysis and artificial neural networks; Energy 36(8) 53565365 .

Marques Filho E P, Oliveira A P, Vita W A, Mesquita F, Codato G, Escobedo J, Cassol M and França J 2016 Global, diffuse and direct solar radiation at the surface in the city of Rio de Janeiro: Observational characterization and empirical modelling; Renew. Energy 91 $64-74$.

Mallet A, Mekki H, Mesa A and Kalogirou S A 2011 FPGAbased implementation of intelligent predictor for global solar irradiation, Part I: Theory and simulation; Expert Syst. Appl. 38(3) 2668-2685.

Mishra A, Kaushika N D, Zhang G and Zhou J 2008 Artificial neural network model for the estimation of direct solar radiation in the Indian zone; Int. J. Sustain. Energy $\mathbf{2 7 ( 3 )}$ 95-103.

Mohammadi K, Shamshirband S, Tong C W, Alam K A and Petković D 2015 Potential of adaptive neuro-fuzzy system for prediction of daily global solar radiation by day of the year; Energy Convers. Manag. 93 406-413.

Müller B, Reinhardt J and Strickland M 1995 Neural Networks - An Introduction; 2nd edn, Springer, Berlin, Heidelberg, New York.

Quej V H, Almorox J, Ibrakhimov M and Saito L 2016 Empirical models for estimating daily global solar radiation in Yucatán peninsula, Mexico; Energy Convers. Manag. 110 448-456.

Sabziparvar A A 2008 A simple formula for estimating global solar radiation in central arid deserts of Iran; Renew. Energy 33(5) 1002-1010.

Takagi T and Sugeno M 1985 Fuzzy identification of systems and its applications to modeling and control; IEEE Trans. Syst. Man. Cybern. 1 116-132.

Wang P P, Ruan D and Kerre E E 2007 Fuzzy Logic: A Spectrum of Theoretical \& Practical Issues; Springer, Berlin.

Yacef R, Mellit A, Belaid S and Şen Z 2014 New combined models for estimating daily global solar radiation from measured air temperature in semi-arid climates: Application in Ghardaia, Algeria; Energy Convers. Manag. 79 606-615.

Yao W, Li Z, Xiu T, Lu Y and Li X 2015 New decomposition models to estimate hourly global solar radiation from the daily value; Sol. Energy 120 87-99. 